\title{
The Role of Ferric(III) Oxide in Poly-(1,4-Phenylene Sulphide) Curing. EPR and X-ray Studies
}

\author{
M. WeJchan-JUdeK ${ }^{a}$, S.K. HofFmanN ${ }^{b, *}$, J. GOSLAR $^{b}$ \\ AND J. GARBARCZYK ${ }^{a}$ \\ ${ }^{a}$ Poznan University of Technology, Polymer Physics and Crystallography Lab. \\ Skłodowskiej Curie 1, 60-965 Poznań, Poland \\ ${ }^{b}$ Institute for Molecular Physics, Polish Academy of Sciences \\ Smoluchowskiego 17, 60-179 Poznań, Poland

\begin{abstract}
Commercially available poly-(1,4-phenylene sulfide) = PPS with trade names TEDUR and RYTON contain a great amount of Fe(III) (order of $10^{20} \mathrm{Fe} /$ gram) as shown by electron spin resonance spectra. The curing of the pure and Fe-doped $\left(0.2 \% \mathrm{Fe}_{2} \mathrm{O}_{3}\right)$ PPS polymers proves that $\mathrm{Fe}(\mathrm{III})$ can be used for improvement of the PPS strength by increasing the polymer cross-linking and a decrease in the polymer crystallinity degree as shown by X-ray diffraction.
\end{abstract}

PACS numbers: 76.30.- $-\mathrm{v}, 61.41 .+\mathrm{e}$

\section{Introduction}

Poly-(1,4-phenylene sulfide) $\equiv$ PPS (Fig. 1) is an engineering high performance thermoplastic polymer with a high degree of crystallinity (typically $65 \%$ ). It possesses excellent chemical stability, flame resistance, excellent mechanical strength and is used as anti-adhesive, corrosion resistant coatings and as moulding resins as well as matrix for thermoplastic composites in electronic and automotive industries [1]. PPS doped with iodine exhibits a good $p$-type conductivity of the order of $10^{-2} \mathrm{~S} / \mathrm{m}[2,3]$. Poly-(1,4-phenylene sulfide) is photosensitive and

${ }^{*}$ corresponding author; e-mail: skh@ifmpan.poznan.pl 


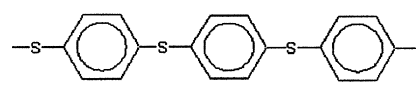

Fig. 1. Poly-(1,4-phenylene sulphide $)=$ PPS.

thus to avoid photodegradation the protective agents are added photostabilizing the polymer against UV light [4]. At room temperature PPS is in the solid state with a glass transition temperature $T_{\mathrm{g}}=363 \mathrm{~K}$. A thermal treatment significantly affects polymer properties [5-9] and molecular dynamics [10] with recrystallization temperature $T_{\mathrm{k}}=400 \mathrm{~K}$. The melting point of polymer is $T_{\mathrm{m}}=553-565 \mathrm{~K}$ depending on the molecular weight [1]. PPS crystalllizes in the orthorhombic system [11]. Above the melting point the curing reaction appears with mechanisms being currently under discussion. The curing strongly improves the PPS properties by an increase in its molecular weight, toughness, ductility resistance, and organic solvent resistance. A role of oxygen as hydrogen abstractor during curing at the air was already explained [9]. In our previous works such mechanism was confirmed in the case of curing without oxygen but in the presence of some quinones [12].

In this paper we report of studies in an attempt to gain further information on the mechanism of PPS curing in the presence of ferric(III) oxide which we stated as an additive or impurity in the commercial PPS under trade name RYTON and TEDUR.

\section{Experimental}

The pristine materials of poly-(1,4-phenylene sulfide) were obtained as RYTON from Phillips Petroleum Co. and as TEDUR from Albis. The parent materials were purified by extraction with organic solvents and with hydrochloride acid to remove the paramagnetic ions contaminations. The curing was performed in nitrogen or air atmosphere at $573 \mathrm{~K}$ for 40 minutes. Some samples were doped with $\mathrm{Fe}_{2} \mathrm{O}_{3}(0.2 \%)$. The crystallinity of PPS was analyzed by means of wide angle X-ray scattering (WAXS) using $\mathrm{Cu} K_{\alpha}$ radiation. The X-ray diffraction pattern was recorded in the angle range of $8-30^{\circ}(2 \Theta)$.

Electron spin resonance (ESR) spectra were recorded at room temperature and at $77 \mathrm{~K}$ on a Radiopan SE/X-2547 spectrometer at X-band with a cylindrical $\mathrm{TE}_{011}$ cavity and $100 \mathrm{kHz}$ magnetic modulation. The concentration of free radicals and $\mathrm{Fe}(\mathrm{III})$ ions was determined from EPR line intensity with respect to ultramarine blue standard signal.

\section{Results and discussion}

Pristine material samples display relatively strong ESR spectra consisting of two different signals - from free radicals and from $\mathrm{Fe}(\mathrm{III})$ ions as is shown in Fig. 2 and Fig. 3 for TEDUR and RYTON, respectively. 

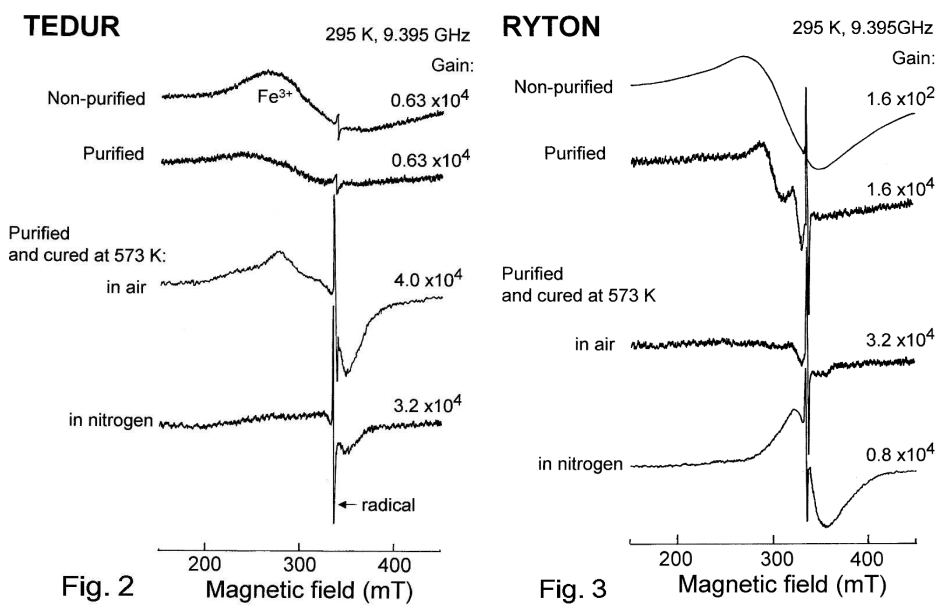

Fig. 2. Room temperature ESR spectra of TEDUR samples: non-purified, purified, and cured in air or nitrogen atmosphere.

Fig. 3. Room temperature ESR spectra of RYTON samples: non-purified, purified, and cured in air or nitrogen atmosphere.

Free radical ESR signal at room temperature is a narrow, slightly asymmetric line with the linewidth $\Delta B_{\mathrm{pp}}=0.6 \mathrm{mT}$ and $g$-factor $g=2.0036$. The line narrows at $77 \mathrm{~K}$ displaying an axial symmetry of the $g$-tensor (Fig. 4 ) with parameters: $g_{\|}=2.0046(4)$ and $g_{\perp}=2.0028(2)(\langle g\rangle=2.0034)$. Similar free radical signals at $g=2.0037$ were observed also in synthesized PPS samples with a concentration of $8 \times 10^{6}$ spins/gram [3].

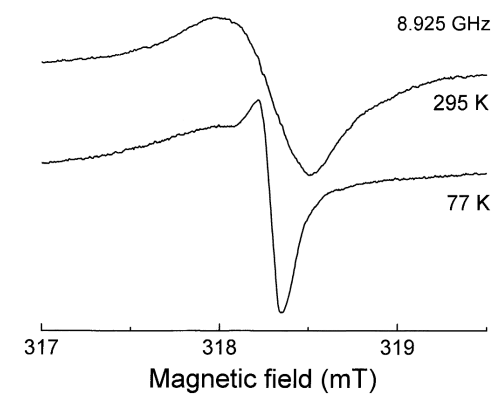

Fig. 4. ESR spectrum of free radicals at room and liquid nitrogen temperature.

The $g$-factors indicates that the unpaired electron is localized on a carbon atom similarly to the oligomeric derivative of the poly(4-hydrazo-diphenylene disulfide) $[13,14]$. Thus this is not a $S^{\bullet}$-radical expected as residual of the polymerization and curing reactions. The absence of the resolved ligand hyperfine structure suggests dynamical averaging of the proton hyperfine splitting. Free radical concentration is two orders of magnitude higher in RYTON 
$\left(2.4 \times 10^{16}\right.$ spins/gram $)$ than in TEDUR and the sample purification does not influences this value (see Table I). But in purified and cured TEDUR the concentration of radicals increases to $2.2-5.6 \times 10^{16}$ spins/gram which is not observed, however, for the RYTON samples.

TABLE I

Concentration of free radicals and $\mathrm{Fe}^{3+}$ in TEDUR and RYTON.

\begin{tabular}{|c|c|c|c|c|}
\hline \multirow{3}{*}{ Sample } & \multicolumn{4}{|c|}{$\begin{array}{c}\text { Concentration of centres (per gram) } \\
\text { [linewidth peak-to-peak (in mT)] }\end{array}$} \\
\hline & \multicolumn{2}{|c|}{ TEDUR } & \multicolumn{2}{|c|}{ RYTON } \\
\hline & radicals & $\mathrm{Fe}^{3+}$ & radicals & $\mathrm{Fe}^{3+}$ \\
\hline \multicolumn{5}{|c|}{ Pristine materials } \\
\hline non-purified & about $10^{14}$ & $\begin{array}{c}1.0 \times 10^{20} \\
{[90 \mathrm{mT}]}\end{array}$ & $2.4 \times 10^{16}$ & $\begin{array}{c}3.8 \times 10^{21} \\
{[74 \mathrm{mT}]}\end{array}$ \\
\hline purified & about $10^{14}$ & $\begin{array}{l}8 \times 10^{18} \\
{[110 \mathrm{mT}]}\end{array}$ & $2.0 \times 10^{16}$ & $\begin{array}{c}\text { very weak } \\
\text { signal } \sim 10^{17}\end{array}$ \\
\hline \multicolumn{5}{|c|}{ Purified and cured (cross-linked) } \\
\hline in air & $2.2 \times 10^{16}$ & $\begin{array}{c}\text { weak } \mathrm{Fe}^{3+} \\
\text { and } \mathrm{Cu}^{2+} \text { lines }\end{array}$ & $3.1 \times 10^{16}$ & $\begin{array}{c}3.3 \times 10^{18} \\
{[33 \mathrm{mT}]}\end{array}$ \\
\hline in nitrogen & $5.6 \times 10^{16}$ & $\begin{array}{c}3.0 \times 10^{18} \\
{[27 \mathrm{mT}]}\end{array}$ & $4.0 \times 10^{16}$ & $\begin{array}{c}4.7 \times 10^{19} \\
{[35 \mathrm{mT}]}\end{array}$ \\
\hline with $\mathrm{Fe}_{2} \mathrm{O}_{3}$ in air & $2.3 \times 10^{16}$ & $\begin{array}{l}1.3 \times 10^{21} \\
{[107 \mathrm{mT}]}\end{array}$ & $3.3 \times 10^{16}$ & $\begin{array}{l}3.5 \times 10^{20} \\
{[102 \mathrm{mT}]}\end{array}$ \\
\hline $\begin{array}{l}\text { with } \mathrm{Fe}_{2} \mathrm{O}_{3} \text { in } \\
\text { nitrogen }\end{array}$ & $2.5 \times 10^{16}$ & $\begin{array}{l}0.8 \times 10^{21} \\
{[120 \mathrm{mT}]}\end{array}$ & $0.6 \times 10^{16}$ & $\begin{array}{l}1.3 \times 10^{22} \\
{[117 \mathrm{mT}]}\end{array}$ \\
\hline
\end{tabular}

Errors: in concentration $\pm 25 \%$; in linewidth $\pm 5 \mathrm{mT}$.

Unexpectedly, strong EPR signals typical of $\mathrm{Fe}(\mathrm{III})$ we have found in TEDUR and RYTON. However in RYTON the Fe(III) ion concentration is 40 times higher than in TEDUR (see Table I). This indicates that in RYTON the iron is not simply a contamination but an additive rather intentionally introduced by producers to improve polymer properties. The Fe(III) EPR lines are very broad (about $100 \mathrm{mT}$ ) and located around $g=2.21$. These are typical spectra of $\mathrm{Fe}(\mathrm{III})$ clusters with distributed EPR parameters [15] in which Fe(III) ions are coupled by exchange and dipolar interaction. After purification the amount of Fe dropped a few order of magnitudes and new EPR signals disclosed. These are signals from individual non-coupled high-spin Fe(III) complexes located at $g=2.0$ (with linewidth about $30 \mathrm{mT}$ ) and signals which seem to arise from $\mathrm{Cu}(\mathrm{II})$ contaminations.

The purified samples were cured at $573 \mathrm{~K}$ in air and nitrogen atmosphere. Some of purified samples were intentionally doped with $\mathrm{Fe}_{2} \mathrm{O}_{3}(0.2 \%)$ and also 
cured in air and nitrogen. The EPR spectra of the cured samples with $\mathrm{Fe}_{2} \mathrm{O}_{3}$ are shown in Fig. 5 and their parameters are collected in Table I. The Fe(III) spectra are similar to those in the starting non-purified materials and origin from the clusters.

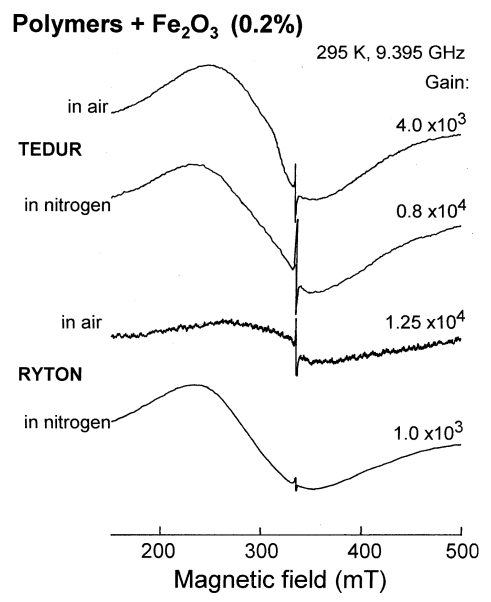

Fig. 5. ESR spectra of polymers doped with $\mathrm{Fe}_{2} \mathrm{O}_{3}$ cured in air and nitrogen atmosphere.

The X-ray results well correspond with Brady's [16] data describing the influence of PPS curing on its crystallinity (Table II). A comparison of the pure and Fe-doped polymers after curing indicates stronger cross-linking and decreasing of crystallinity degree of the Fe-doped polymer.

TABLE II

PPS crystallinity after curing.

\begin{tabular}{l|c|c}
\hline \hline \multirow{2}{*}{ Polymer } & \multicolumn{2}{|c}{ Crystallinity degree [\%] } \\
\cline { 2 - 3 } & in nitrogen & in air \\
\hline RYTON $^{a}$ unpurified & 49 & 43 \\
RYTON purified $^{b}$ & 43 & 37 \\
$\mathrm{TEDUR}^{b}$ unpurified & 42 & 39 \\
$\mathrm{TEDUR}$ purified & 38 & 19 \\
$\mathrm{RYTON}^{c}+\mathrm{Fe}_{2} \mathrm{O}_{3}$ & 6 & 5 \\
$\mathrm{TEDUR}^{d}+\mathrm{Fe}_{2} \mathrm{O}_{3}$ & 2 & 1 \\
\hline${ }^{a}$ crystallinity degree of uncured RYTON $-61 \%$, \\
${ }^{b}$ crystallinity degree of uncured TEDUR - 63\%, \\
${ }_{c}^{c, d}$ purified polymers.
\end{tabular}




\section{References}

[1] B.G. Risch, S. Srinivas, G.L. Wilkes, J.F. Geibel, C. Ash, S. White, M. Hicks, Polymer 37, 3623 (1996).

[2] K.F. Schech, J.F. Chance, K.E. Pfeiffer, Macromolecules 18, 2389 (1985).

[3] L. Kreja, F. Rozpłoch, A. Warszawski, Angew. Makromol. Chemie 160, 163 (2003).

[4] P.K. Das, P.J. DesLauriers, D.R. Fahey, F.K. Wood, F.J. Cornforth, Polymer Degr. Stab. 48, 1 (1995)

[5] G.F.L. Ehlers, K.R. Fisch, W.R. Powell, J. Pol. Sci. 7, 2955 (1969).

[6] N.S.J. Christopher, J.Z. Cotter, G.J. Knight, W.W. Wright, J. Appl. Polym. Sci. 16, 3207 (1972).

[7] W.B. Gavalian, N.Z. Nedelkin, Y.W. Zhuravleva, S.S. Pavlova, W.A. Sergeyev, Wysokomol. Soyed. B XX, 768 (1978).

[8] R.T. Hawkins, Macromolecules 9, 189 (1976).

[9] A.B. Port, R.H. Still, Polym. Degr. Stab. 2, 1 (1980).

[10] J. Jurga, A. Wozniak-Braszak, Z. Fojud, K. Jurga, Sol. State Nucl. Magn. Res. 25, 47 (2004).

[11] B.J. Tabor, E.P. Magree, J. Boon, Eur. Polym. J. 7, 1127 (1971); J.N. Hay, D.A. Luck, Polymer 42, 8297 (2001).

[12] M. Wejchan-Judek, B. Perkowska, B. Karska, J. Mat. Sci. Lett. 12, 433 (1993).

[13] S.K. Hoffmann, I. Polus, W. Hilczer, J. Goslar, S. Kiczka, B. Doczekalska, Pol. J. Chem. 77, 87 (2003).

[14] S.K. Hoffmann, W. Hilczer, J. Goslar, S. Kiczka, I. Polus, Phys. Chem. Chem. Phys. 4, 4944 (2002).

[15] G.A. Kortweg, L.L. vanReijen, J. Magn. Res. 44, 159 (1981).

[16] D.G. Brady, J. Appl. Chem. 20, 2541 (1976). 